\title{
RESEARCH
}

Open Access

\section{Determinants of postnatal care utilization in sub-Saharan Africa: a meta and multilevel analysis of data from 36 sub- Saharan countries}

Zemenu Tadesse Tessema ${ }^{1 *}$ (D), Lake Yazachew ${ }^{2}$, Getayeneh Antehunegn Tesema ${ }^{1}$ and Achamyeleh Birhanu Teshale ${ }^{1}$

\begin{abstract}
Introduction: Globally, over $65 \%$ of maternal deaths occur during the first 42 days of postpartum while the same proportion of neonatal deaths occur during the first 7 days of life. In sab- Saharan Africa, 4.7 million mothers, newborns, and children die on annual basis. As to our knowledge, there is no study on postnatal care utilization that incorporates all sub-Saharan Africa countries that had DHS data. Therefore, this study aimed at identifying pooled magnitude and determinants of postnatal care utilization in sub-Saharan Africa.
\end{abstract}

Method: A population-based cross-sectional study from the most recent Demographic and Health Surveys data from the period of 2006 to 2018 of 36 SSA countries were used. A total weighted sample of 286,255 reproductive-age women who gave birth 5 years preceding the survey were included in the study. A meta-analysis of DHS data of each SubSaharan countries was conducted to generate pooled magnitude and a forest plot was used to present it. A multilevel logistic regression model was fitted to identify determinants of postnatal care utilization. The AOR (Adjusted Odds Ratio) with their $95 \% \mathrm{Cl}$ and $p$-value $\ell 0.05$ was used to declare that determinates associated with postnatal care utilization.

Result: The pooled magnitude of postnatal care utilization in sub-Saharan Africa countries was 52.48\% [95\% Cl: 52.33, 52.63], with the highest postnatal care utilization in the Central Region of Africa (73.51\%) and the low postnatal care utilization in Eastern Regions of Africa (31.71\%). In the multilevel logistic regression model region, residence, age group, maternal education, maternal occupation, media exposure, ANC visit, place of delivery, and accessing health care were determinants of postnatal care utilization in Sub-Saharan Africa.

(Continued on next page)

\footnotetext{
* Correspondence: zemenut1979@gmail.com

'Department of Epidemiology and Biostatistics, Institute of Public Health, College of Medicine and Health Sciences, University of Gondar, Gondar, Ethiopia

Full list of author information is available at the end of the article
}

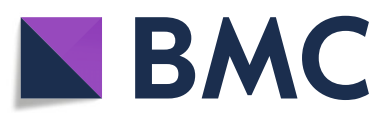

N The Author(s). 2020 Open Access This article is licensed under a Creative Commons Attribution 4.0 International License, which permits use, sharing, adaptation, distribution and reproduction in any medium or format, as long as you give appropriate credit to the original author(s) and the source, provide a link to the Creative Commons licence, and indicate if changes were made. The images or other third party material in this article are included in the article"s Creative Commons licence, unless indicated otherwise in a credit line to the material. If material is not included in the article"s Creative Commons licence and your intended use is not permitted by statutory regulation or exceeds the permitted use, you will need to obtain permission directly from the copyright holder. To view a copy of this licence, visit http://creativecommons.org/licenses/by/4.0/ The Creative Commons Public Domain Dedication waiver (http://creativecommons.org/publicdomain/zero/1.0/) applies to the data made available in this article, unless otherwise stated in a credit line to the data. 


\begin{abstract}
(Continued from previous page)
Conclusion: The coverage of postnatal care service utilization was low with high disparities among the region. Being in rural residence, young age group, low education level, had no occupation, not exposed to media, a big problem to access health care, not had ANC visit, and home delivery was associated with low postnatal care service utilization. This study evidenced that there is a wide gap in postnatal care utilization between SSA countries. Special attention is required to improve health accessibility, utilization, and quality of maternal health services to increase postnatal care service utilization in the region.
\end{abstract}

Keywords: Postnatal care, Sub-Saharan Africa, Multilevel, Determinants

\section{Introduction}

Our world health systems are challenged with sustained and major maternal mortality. According to the World Health Organization (WHO), 289,000 women die from complications related to pregnancy, labor and delivery, and the postpartum period every year globally $[1,2]$. On the other hand, over 1 million neonates die soon after birth every year worldwide, making the day of birth the most critical day for neonates all over the world $[3,4]$.

Over $65 \%$ of maternal deaths occur during the first 42 days of postpartum while the same proportion of neonatal deaths occur during the first 7 days of life. However, almost all (99\%) of these maternal and neonatal deaths occur in developing countries with the highest deaths in south Asia and sub-Saharan Africa. In developing countries, maternal death was 15 times higher than in developed countries. The highest maternal and child deaths take place in sub-Saharan Africa, 500 maternal deaths per 100,000 live births every year $[1,2,5]$.

In sab Saharan Africa, mothers are more likely to die due to pregnancy, delivery, and post-delivery related conditions. Moreover, 4.7 million mothers, newborns, and children die on annual basis in sub-Saharan Africa: pregnancy and delivery-initiated complications account for 265,000 maternal deaths and 3,192,000 child deaths who are between the age of 1 month and 5 years $[3,4,6,7]$.

Maternal health service utilization is an effective intervention to overcome maternal and child health-related complications. Likewise, postnatal care service is a basic component of the continuum of maternal health services. According to $\mathrm{WHO}$ a postnatal period is defined as the time from an hour after the delivery of the placenta through 6 weeks after the delivery of a child. Postnatal care (PNC) comprises of services given to mothers and neonates right after delivery and up to 42 days of postpartum to ensure optimum health for the mother and her infant $[5,8]$.

Worldwide, PNC has been declared to be a vital maternal health service to keep and promote the health and long life of a mother and newborn. Furthermore, health experts have a chance to detect, follow, and handle the health conditions of both the mother and newborn during postnatal service [9]. Also, post-natal services are the key strategies to prevent the emerging of physical and mental deterioration among post-natal mothers [6].

Following tremendous efforts, antenatal care (ANC) has shown an advanced change across years, while PNC still leftovers below the tolerable speed of improvement in many developing countries. Understanding the role of PNC in the continuum of maternal care during the post-natal period made implementation of policies that intended to improve maternal and newborn health [8].

The postpartum period is a life-threatening time for both mothers and newborns. It is also a time to occur most clinically important changes in the mother's and newborns' bodies. Especially, in developing countries [4], PNC is a key maternal health service in reducing maternal morbidity and mortality including sab Saharan Africa. Fail to use this service may bring avoidable deaths and sequelae as well as missed opportunities to promote maternal and child health [10].

Hence, WHO recommends that, when labour is attended in a health facility, for a simple vaginal delivery, ordinary newborns must be given a minimum of $24 \mathrm{~h}$ care. Whereas, if the birth happens out of health facility, the first postnatal visit must be within the first $24 \mathrm{~h}$ of delivery. Irrespective of the place of delivery, at least three other postnatal visits are arranged for all mothers and newborns, on day $3(48-72 \mathrm{~h})$, between the 1st and 2nd weeks, and 6 weeks after delivery. Nevertheless, less than a quarter of newborns in less developed countries receive PNC within $48 \mathrm{~h}$ of delivery [4].

According to UNICEF's brief report of 2019, 63\% of mothers and just $48 \%$ of newborns worldwide received a post-natal health check within the prescribed timeframe [11]. However, in Africa, health institutions are not visited by most women and newborns after birth. This implies that post-natal services are among neglected agendas than all other reproductive and child health programs. The magnitude of postnatal care service utilization is very low, for instance, $47 \%$ in Kenya, $41.2 \%$ in Nigeria, $43.53 \%$ in Tanzania, 43, 55\% in Zambia, 57.5\% in Ethiopia, and it is highly variable across sab Saharan countries and unconvincing for interventions $[4,10,12]$. 
Evidence showed that PNC services utilization is influenced by factors such as the age of the mother, level of education of the women, occupational status of women and spouses, household economic status, place of delivery, birth order, awareness about obstetric related danger sign, and awareness about PNC services. However, factors influencing PNC services utilization vary from place to place [13, 14]. In sab Saharan Africa, various factors have been identified as significantly associated with postnatal care service use. Educational level of the mother, wealth quintile of the household, residence, gravidity, ANC visit, and place of delivery were identified as factors influencing postnatal care service utilization. But in sub-Saharan Africa, utilization of postnatal care service and associated factors are extremely variable and unsatisfying to design effective strategies $[4,12,15]$.

In the previous studies, the logistic regression model was used, which cannot address a problem of nonindependence $[1,3,13,16,17]$. But in this study, we used the multilevel model, which can handle both individual and community-level characteristics.

Moreover, there are many individual and communitylevel characteristics that are likely to influence postnatal care service utilization. Identifying, examining, and understanding these determinants is a first step in exploring strategies to reduce maternal mortality.

Therefore, a more advanced model, the multilevel logistic model was used to systematically identify and synthesize to quantify the pooled magnitude of postnatal care service utilization and determinants among reproductive-age women who gave live birth in sab Saharan Africa.

\section{Method}

\section{Data source}

The data used in this study were the most recent Demographic and Health Surveys (DHS) data compiled in the following sub-Saharan Africa countries (Angola, Benin, Burkina-Faso, Burundi, Cameroon, Chad, Comoros, Congo, Cote d'Ivoire, Democratic Republic of Congo, Ethiopia, Gabon, Gambia, Ghana, Guinea, Kenya, Lesotho, Liberia, Madagascar, Malawi, Mali, Mozambique, Namibia, Niger, Nigeria, Rwanda, Sao Tome \& Principe, Senegal, Sierra Leone, Swaziland, Tanzania, Togo, Uganda, Zambia, Zimbabwe South Africa) from 2006 to 2018 (Table 1). These datasets were appended together to determine the pooled magnitude and determinants of postnatal care service utilization across the Sub-Saharan Africa countries. The DHS is a nationwide representative survey that collects data on basic health indicators like mortality, morbidity, family planning service utilization, fertility, maternal and child health. The data were derived from the measure DHS
Table 1 Pooled Demographic and Health Surveys (DHS) data from 36 sub-Saharan countries, 2006†2018

\begin{tabular}{|c|c|c|}
\hline Country & DHS year & Sample size $(286,255)$ \\
\hline Southern Region of Africa & & 9957 \\
\hline Lesotho & 2014 & 2575 \\
\hline Namibia & 2013 & 3875 \\
\hline Swaziland & 2006/07 & 514 \\
\hline South Africa & 2016 & 3035 \\
\hline Central Region of Africa & & 88,207 \\
\hline Angola & 2015/16 & 14,379 \\
\hline DR Congo & $2013 / 14$ & 18,827 \\
\hline Congo & $2011 / 12$ & 10,819 \\
\hline Cameroon & 2011 & 15,426 \\
\hline Gabon & 2012 & 8421 \\
\hline Sao Tome \& Principe & 2008/09 & 2615 \\
\hline Chad & 2014/15 & 17,719 \\
\hline Eastern Region of Arica & & 90,524 \\
\hline Burundi & 2010 & 8894 \\
\hline Ethiopia & 2016 & 7590 \\
\hline Kenya & 2014 & 6864 \\
\hline Comoros & 2012 & 2064 \\
\hline Madagascar & 2008/09 & 5395 \\
\hline Malawi & 2015/16 & 13,469 \\
\hline Mozambique & 2011 & 13,745 \\
\hline Rwanda & $2014 / 15$ & 2962 \\
\hline Tanzania & $2015 / 16$ & 7077 \\
\hline Uganda & 2011 & 10,152 \\
\hline Zambia & 2018 & 7324 \\
\hline Zimbabwe & 2013/14 & 4983 \\
\hline Western Region of Africa & & 97,567 \\
\hline Burkina-Faso & 2010 & 10,107 \\
\hline Benin & 2017 & 9030 \\
\hline Cote d'Ivoire & 2011 & 5223 \\
\hline Ghana & 2014 & 4141 \\
\hline Gambia & 2013 & 2060 \\
\hline Guinea & 2018 & 5464 \\
\hline Liberia & 2013 & 4769 \\
\hline Mali & 2018 & 6604 \\
\hline Nigeria & 2018 & 21,801 \\
\hline Niger & 2012 & 8002 \\
\hline Sierra Leone & 2010/11 & 8647 \\
\hline Senegal & 2010/11 & 6864 \\
\hline Togo & $2013 / 14$ & 4850 \\
\hline
\end{tabular}


program. Each country's survey consists of various datasets including men, women, children, birth, and household datasets, for this study IR file, was used.

The IR file contains all the collected data in the Woman's Questionnaire for de facto women plus some variables from the Household Questionnaire. Up to 20 births in the birth history, and up to 6 children under age 5 , for whom pregnancy and postnatal care, as well as immunization, health, and nutrition data, were collected, can be found as repeated variables in this file. This dataset use for most woman-level analysis including marriage and sexual activity, fertility, and fertility preferences, family planning, anthropometry and anemia in women, malaria prevention for women, HIV/AIDS, women's empowerment, adult and maternal mortality, and domestic violence.

The DHS uses a two-stage stratified sampling technique to select the study participants. We pooled 36 DHS surveys done in the Sub-Saharan Africa countries and a weighted sample of 286,255 reproductive-age women who gave birth in the last 5 years preceding the survey was included in the study.

\section{Measurements of variables \\ Outcome variable}

The outcome variable for this study was postnatal care services utilization. The variable is generated using WHO definitions of postnatal care services utilization which takes into account attendance of postnatal care checks by a health professional within 42 days of birth [1]. The outcome variable was binary and was coded as " 1 " if women got postnatal care service and"0" otherwise.

\section{Explanatory variables}

Based on known facts and literature the independent variables: There are two types of variables considered for this study. The level one variable or individual-level variables and level two variables.

Level 1 or individual level variable include maternal age, marital status, maternal education, occupational status, ANC visit, place of delivery, health care access, birth order, wealth index, and parity

Level 2 or community level variable like country, residence, and Region (East, West, Central, and South)

\section{Data management and analysis}

We pooled the data from the 36 sub-Saharan African countries together after extracting the variables based on literature. Before any statistical analysis, the data were weighted using sampling weight, primary sampling unit, and strata to restore the representativeness of the survey and take sampling design when calculating standard errors and reliable estimates. Cross tabulations and summary statistics were done using STATA version 14 software. The pooled prevalence of postnatal care service utilization with 95\% Confidence Interval (CI) was reported for sub- Saharan Africa Countries from 2006 to 2018. Variables with $p$-value $<0.2$ in the bi-variable analysis were considered in the multilevel logistic regression model. Adjusted Odds Ratios (AOR) with a 95\% Confidence Interval $(\mathrm{CI})$ and $\mathrm{p}$-value $\leq 0.05$ in the multilevel logistic model were used to declare significant factors associated with postnatal care utilization.

\section{Statistical modeling}

For the determinants factors, the DHS data had a hierarchical structure, this violates the independence of observations and equal variance assumption of the traditional logistic regression model. Hence women are nested within a cluster and we expect that women within the same cluster may be more similar to each other than women in the rest of the country. This implies that there is a need to take into account the between cluster variability by using advanced models. Therefore, a multilevel logistic regression model (both fixed and random effect) was fitted. Since the outcome variable was binary, standard logistic regression and multilevel logistic regression models were fitted. In the multilevel logistic regression model, we ran four models to estimate both fixed effects of the individual and community-level factors and random intercept of between-cluster variation.

Empty model: the model analyzed without any factor variables, to test the random effect of between-cluster variability. Derived from the between-cluster and withincluster variability, intra-class correlation coefficient (ICC) was estimated to determine if the data justified using a multilevel approach for analyses by depicting the magnitude of between-cluster variability.

Individual-level factors model: The second model examined effects of individual characteristics on postnatal care utilization. Besides, the ICC was estimated and observed if there was a decline in the between-cluster variability upon adding individual factors to the empty model.

Community-level factors model: This model contained only characteristics of clusters, not individuals. The unit of analysis for this model was the cluster.

Combined model: The important characteristics of individual women and clusters were concurrently fitted to one model to reveal their net fixed and random effects.

Model comparison and fitness were done based on the Intra-class Correlation Coefficient (ICC), Likelihood Ratio (LR) test, Median Odds Ratio (MOR), and deviance (-2LLR) values since the models were nested. The model with the lowest deviance was chosen.

Four models were fitted null model (models without the explanatory variables), the model I (models include community-level variables, model II (models include 
individual-level variable)), and Model III (models include both individual and community level variables) were fitted to select the best fit model for the data using LLR and Deviance. Model III which includes both individual and community level variable was selected because of its highest LLR and Smallest deviance (Table 3).

\section{Ethics consideration}

Permission to get access to the data was obtained from the measure DHS program online request from http://www.dhsprogram.com.website and the data used were publicly available with no personal identifier.

\section{Result}

In this study, 285,255 women who gave birth 5 years preceding the survey in 36 sub-Saharan Africa countries were included. Of these, the largest study participants 97,567(34.08\%) were from Western Africa Region and the smallest study participants $9957(3.48 \%)$ were from Southern Regions of Africa. The majority of study participants $181,426(63.38 \%)$ were rural residents. The median age women included in his study was 28.8 $(\mathrm{IQR}=7.2)$ years in which $117,219(40.95)$ of them under age category $25-34$. Thirty-five percent of women and 36 $\%$ of men had no formal education. More than one-third of women 116,353(40.65) were under poor wealth status. Majority 255,498(89.26\%) of women had antenatal care visits during their pregnancy. Seventy percent of women deliver their child at a health institution (Table 2).

\section{Pooled prevalence of postnatal care utilization}

The pooled magnitude of postnatal care service utilization in sub-Saharan Africa countries was 52.48\% [95\% CI: 52.23, 52.63], with the highest postnatal care service utilization in central region of Africa (73.51\%) and the lowest postnatal care service utilization in eastern regions of Africa (31.71\%). The sub-group analysis result evidenced that in southern regions of Africa highest utilization of postnatal care service $81.48 \%$ were recorded in Lesotho and the smallest number of postnatal care service utilization $20.44 \%$ were recorded in Swaziland. In the central regions of Africa highest postnatal care utilization $85.52 \%$ were recorded in Cameroon and the lowest postnatal care service utilization 48.03\% were from Chad. In Eastern regions of Africa highest postnatal care service utilization $84.17 \%$ were recorded in Zimbabwe and the lowest postnatal care service utilization $8.33 \%$ were from Ethiopia. In the western regions of Africa the highest postnatal care service utilization $81.64 \%$ were from Burkina Faso and the lowest utilization of postnatal care service utilization 19.14 were from Benin (Fig. 1).

\section{Determinants of postnatal care utilization Random effect estimates}

The model fitted for this study was multilevel multivariable logistic regression. There are two parts of estimates in this model. The random-effects estimates and fixed estimate. The random effect estimates were observed by fitting four models (Null model, Model I, Model II, Model III). The empty model shows that there was a significant variation in the likelihood of postnatal care utilization within sub-Saharan Africa Countries $\left({ }^{2}=\right.$ $0.31, p<0.001)$. The ICC in the empty model implied that $8.66 \%$ of the total variation in postnatal care utilization was contributed to the difference between Countries. The cluster-level variance was expressed as ICC and MOR. Moreover, the MOR was 1.62 (95\%CI: $1.57,1.67)$ which implies that the odds of postnatal care service utilization was 1.62 times more likely when women go from low to high-risk countries. In model III (full model adjusted for individual and community level factors) cluster level variance $\left({ }^{2}=0.25, p<0.001\right)$ remained significant but reduced. A total of $17.3 \%$ variability postnatal care utilization can be contributed to the country-level factors. The proportional change in variance $(\mathrm{PCV})$ in this model was $17.30 \%$ which indicated $17.30 \%$ of the Country variance observed in the empty model was explained by both Country and individual level variable (Table 3).

\section{The fixed effects analysis result}

In the multilevel logistic regression model; Sub-Sahara Africa region, residence, age group, maternal education, maternal occupation, media exposure, ANC visit, Place of delivery, and accessing health care were statistically associated with postnatal care utilization in sub-Saharan Africa.

Women lining in central, eastern and, western Africa regions were decrease the likelihood of postnatal care service utilization by 63,49 and $43 \%(\mathrm{AOR}=0.37,95 \%$ CI: $0.35,0.39) \quad(\mathrm{AOR}=0.51,95 \% \mathrm{CI}: 0.48,0.54)$ and (AOR $=0.67,95 \% \mathrm{CI}: 0.63,0.72)$ as compared to women living in southern regions of Africa respectively. Women who reside in urban areas had $1.14(\mathrm{AOR}=1.14,95 \% \mathrm{CI}$ : $1.11,1.17)$ times more likely to utilize postnatal care service than women living in rural areas. The odds of postnatal care service utilization among women of age group 25-34 and 35-49 were 1.07 and 1.15 time higher $1.07(\mathrm{AOR}=1.07,95 \% \mathrm{CI}: 1.04,1.09)$ and $1.15(\mathrm{AOR}=$ $1.15,95 \%$ CI: $1.12,1.19$ ) as compared to women age group 15-24 respectively. Women who had primary and secondary and above educational level had 1.15 (AOR = 1.15, 95\% CI: $1.12,1.18)$ and $1.11(\mathrm{AOR}=1.11,95 \% \mathrm{CI}$ : $1.07,1.11)$ times more likely to utilize postnatal care service than women who had no formal education. The odds of postnatal care service utilization among women 
Table 2 Distribution of postnatal service utilization in sub-Saharan Africa region

\begin{tabular}{|c|c|c|c|c|c|}
\hline \multirow[t]{2}{*}{ Variable } & \multicolumn{2}{|c|}{ Postnatal care Utilization } & \multirow[t]{2}{*}{ Total (\%) } & \multirow{2}{*}{$\begin{array}{l}X- \\
\text { square } \\
\text { value }\end{array}$} & \multirow[t]{2}{*}{$p$-value } \\
\hline & Yes & No & & & \\
\hline \multicolumn{6}{|l|}{ Africa Region } \\
\hline Southern & 6770 & 3187 & $9957(3.48)$ & 98.41 & $<0.001^{*}$ \\
\hline Central & 57,053 & 31,153 & $88,207(30.81)$ & & \\
\hline Eastern & 44,165 & 46,358 & $90,524(31.62)$ & & \\
\hline Western & 48,641 & 48,924 & $97,567(34.08)$ & & \\
\hline \multicolumn{6}{|l|}{ Residence } \\
\hline Rural & 87,787 & 93,638 & $181,426(63.38)$ & 104.44 & $<0.001^{*}$ \\
\hline Urban & 35,985 & 68,843 & $104,829(36.62)$ & & \\
\hline \multicolumn{6}{|l|}{ Age group } \\
\hline $15+24$ & 56,853 & 39,426 & $96,279(33.63)$ & 36.15 & $<0.001^{*}$ \\
\hline $25+34$ & 58,506 & 58,713 & $117,219(40.95)$ & & \\
\hline $35+46$ & 41,271 & 31,485 & $72,756(25.42)$ & & \\
\hline \multicolumn{6}{|l|}{ Maternal education } \\
\hline No education & 46,935 & 56,073 & $103,008(35.98)$ & 134.57 & $<0.001^{*}$ \\
\hline Primary education & 50,139 & 42,819 & $92,959(32.47)$ & & \\
\hline Secondary and above & 59,555 & 30,731 & $90,287(31.54)$ & & \\
\hline \multicolumn{6}{|l|}{ Husband education } \\
\hline No education & 40,652 & 46,701 & $87,354(36.80)$ & 30.12 & $<0.001^{*}$ \\
\hline Primary education & 32,590 & 32,569 & $65,160(27.45)$ & & \\
\hline Secondary and above & 48,379 & 36,488 & $84,867(35.75)$ & & \\
\hline \multicolumn{6}{|l|}{ Maternal Occupation } \\
\hline Had occupation & 108,871 & 94,426 & $83,069(29.02)$ & 196 & $<0.001^{*}$ \\
\hline Had no occupation & 47,871 & 35,198 & 203,185(70.98) & & \\
\hline \multicolumn{6}{|l|}{ Wealth Index } \\
\hline Poor & 55,828 & 60,524 & $116,353(40.65)$ & 68.28 & $<0.001^{*}$ \\
\hline Middle & 30,789 & 25,907 & $56,696(19.18)$ & & \\
\hline Rich & 70,012 & 43,192 & $113,205(39.55)$ & & \\
\hline \multicolumn{6}{|l|}{ Media Exposed } \\
\hline Yes & 115,797 & 74,269 & $190,246(66.47)$ & 162.69 & $<0.001^{*}$ \\
\hline No & 40,647 & 55,341 & $95,968(33.53)$ & & \\
\hline \multicolumn{6}{|l|}{ ANC visit } \\
\hline Yes & 149,922 & 105,576 & $255,498(89.26)$ & 87.35 & $<0.001^{*}$ \\
\hline No & 6690 & 24,042 & $30,732(10.74)$ & & \\
\hline \multicolumn{6}{|l|}{ Place delivery } \\
\hline Home & 28,337 & 53,439 & $81,777(29.17)$ & 92.81 & $<0.001^{*}$ \\
\hline Health Institution & 122,415 & 76,179 & 198,594(70.83) & & \\
\hline \multicolumn{6}{|l|}{ Wanted pregnancy } \\
\hline Yes & 104,349 & 120,881 & $225,230(93.30)$ & 4.19 & $0.041^{*}$ \\
\hline No & 7455 & 8711 & $16,166(6.70)$ & & \\
\hline \multicolumn{6}{|l|}{ Accessing health care } \\
\hline Big problem & 91,608 & 81,345 & $172,954(60.70)$ & 503.34 & $<0.001^{*}$ \\
\hline Not big problem & 63,776 & 48,015 & $111,791(39.26)$ & & \\
\hline
\end{tabular}


Table 2 Distribution of postnatal service utilization in sub-Saharan Africa region (Continued)

\begin{tabular}{|c|c|c|c|c|c|}
\hline \multirow[t]{2}{*}{ Variable } & \multicolumn{2}{|c|}{ Postnatal care Utilization } & \multirow[t]{2}{*}{ Total (\%) } & \multirow{2}{*}{$\begin{array}{l}\mathrm{X} \text { - } \\
\text { square } \\
\text { value }\end{array}$} & \multirow[t]{2}{*}{$p$-value } \\
\hline & Yes & No & & & \\
\hline \multicolumn{6}{|l|}{ Birth Order } \\
\hline 1 & 28,601 & 24,786 & $53,387(18.65)$ & 28.11 & $<0.001^{*}$ \\
\hline $2+4$ & 62,675 & 59,487 & $122,163(42.68)$ & & \\
\hline $5+$ & 65,354 & 45,350 & $110,704(38.67)$ & & \\
\hline \multicolumn{6}{|l|}{ Birth weight } \\
\hline Low birth weight & 18,532 & 24,517 & $43,050(17.83)$ & 320.10 & $<0.001^{*}$ \\
\hline Normal & 93,265 & 105,090 & 198,355(82.17) & & \\
\hline
\end{tabular}

${ }^{*}=$ indicates there is significant association between postnatal care and independent variable

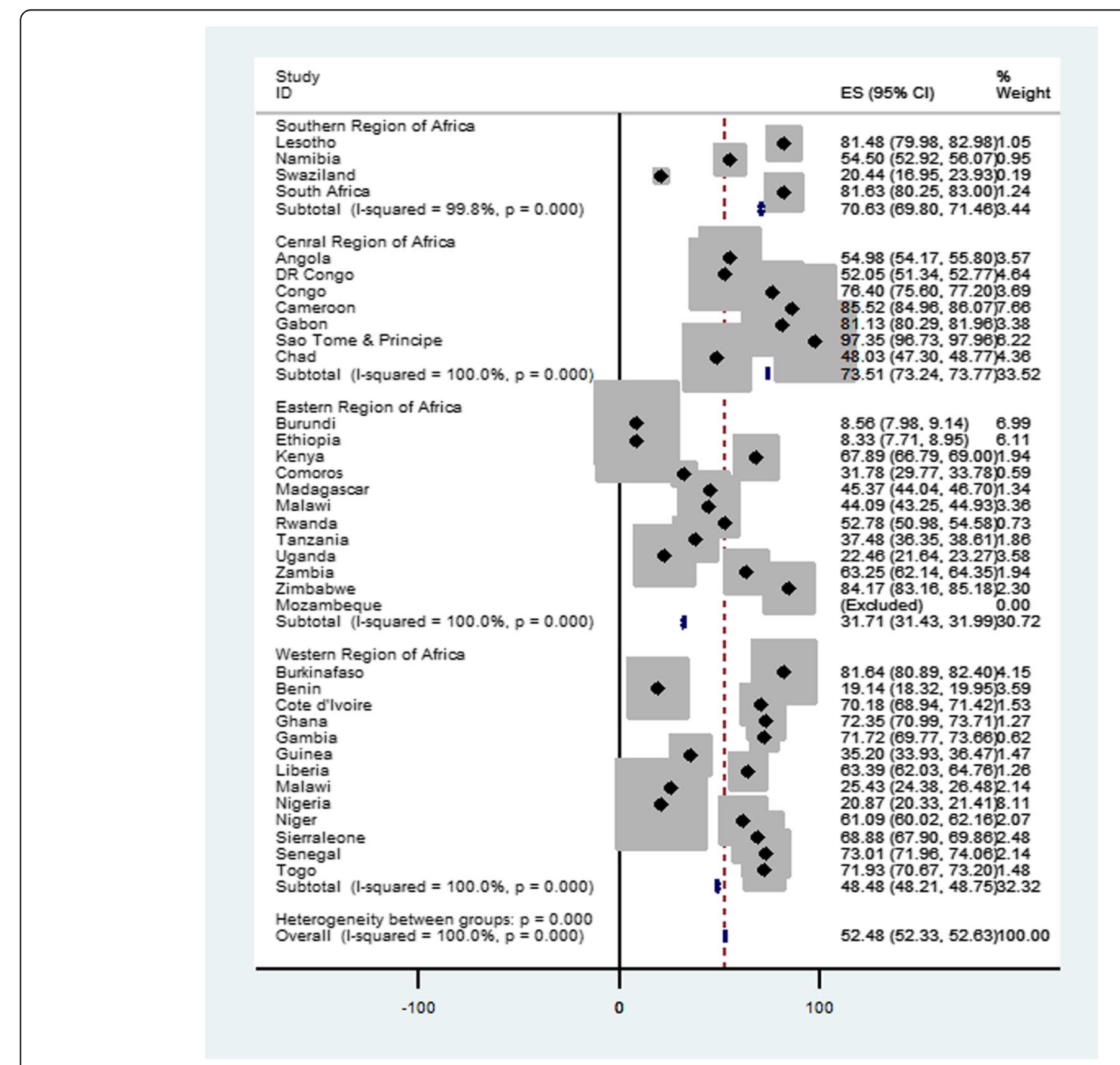

Fig. 1 Forest plot of prevalence of postnatal care utlization in SSA countries 
Table 3 Multilevel multivariable logistic regression model result of postnatal care service utilization in sub-Saharan Africa from 2006 to 2018

\begin{tabular}{|c|c|c|c|c|}
\hline Variable & $\begin{array}{l}\text { Empty Model } \\
\text { AOR(95\%Cl) }\end{array}$ & $\begin{array}{l}\text { Community-level factors model } \\
\text { AOR }(95 \% \mathrm{Cl})\end{array}$ & $\begin{array}{l}\text { Individual-level factors model } \\
\text { AOR }(95 \% \mathrm{Cl})\end{array}$ & $\begin{array}{l}\text { Combined model } \\
\text { AOR( } 95 \% \mathrm{Cl})\end{array}$ \\
\hline \multicolumn{5}{|l|}{ Africa Region } \\
\hline Southern & & 1 & & 1 \\
\hline Central & & $0.78(0.74,0.81)$ & & $0.37(0.35,0.39)^{*}$ \\
\hline Eastern & & $0.51(0.49,0.54)$ & & $0.51(0.48,0.54)^{*}$ \\
\hline Western & & $0.49(0.47,0.52)$ & & $0.67(0.63,0.72)^{*}$ \\
\hline \multicolumn{5}{|l|}{ Residence } \\
\hline Rural & & 1 & & 1 \\
\hline Urban & & $1.72(1.69,1.75)$ & & $1.14(1.11,1.17)^{*}$ \\
\hline \multicolumn{5}{|l|}{ Age group } \\
\hline $15+24$ & & & 1 & 1 \\
\hline $25+34$ & & & $1.10(1.07,1.13)$ & $1.07(1.04,1.09)^{*}$ \\
\hline $35+46$ & & & $1.22(1.18,1.26)$ & $1.15(1.12,1.19)^{*}$ \\
\hline \multicolumn{5}{|l|}{ Maternal education } \\
\hline No education & & & 1 & 1 \\
\hline Primary education & & & $1.03(1.01,1.05)$ & $1.15(1.12,1.18)^{*}$ \\
\hline Secondary and above & & & $1.02(0.99,1.06)$ & $1.11(1.07,1.14)^{*}$ \\
\hline \multicolumn{5}{|l|}{ Husband education } \\
\hline No education & & & 1 & 1 \\
\hline Primary education & & & $0.89(0.87,0.91)$ & $0.98(0.95,1.01)$ \\
\hline Secondary and above & & & $0.86(0.83,0.88)$ & $0.97(0.95,1.02)$ \\
\hline \multicolumn{5}{|l|}{ Maternal Occupation } \\
\hline Had occupation & & & 1 & 1 \\
\hline Had no occupation & & & $1.03(1.01,1.06)$ & $1.04(1.02,1.06)^{*}$ \\
\hline \multicolumn{5}{|l|}{ Wealth Index } \\
\hline Poor & & & 1 & 1 \\
\hline Middle & & & $1.00(.97,1.02)$ & $0.97(0.95,1.01)$ \\
\hline Rich & & & $0.98(0.96,1.01)$ & $0.96(0.94,1.02)$ \\
\hline \multicolumn{5}{|l|}{ Media Exposed } \\
\hline No & & & 1 & 1 \\
\hline Yes & & & $1.85(1.82,1.89)$ & $1.70(1.67,1.74)^{*}$ \\
\hline \multicolumn{5}{|l|}{ ANC visit } \\
\hline No & & & 1 & 1 \\
\hline Yes & & & $3.03(2.95,3.13)$ & $2.93(2.84,3.03)^{*}$ \\
\hline \multicolumn{5}{|l|}{ Place delivery } \\
\hline Home & & & 1 & 1 \\
\hline Health Institution & & & $1.45(1.42,1.48)$ & $1.45(1.42,1.48)^{*}$ \\
\hline \multicolumn{5}{|l|}{ Wanted pregnancy } \\
\hline No & & & 1 & 1 \\
\hline Yes & & & $0.98(0.94,1.02)$ & $1.00(0.96,1.04)$ \\
\hline \multicolumn{5}{|l|}{ Accessing health care } \\
\hline Big problem & & & 1 & 1 \\
\hline Not big problem & & & $1.05(1.03,1.07)$ & $1.04(1.02,1.06)^{*}$ \\
\hline
\end{tabular}

\section{Birth Order}


Table 3 Multilevel multivariable logistic regression model result of postnatal care service utilization in sub-Saharan Africa from 2006 to 2018 (Continued)

\begin{tabular}{|c|c|c|c|c|}
\hline Variable & $\begin{array}{l}\text { Empty Model } \\
\text { AOR(95\%Cl) }\end{array}$ & $\begin{array}{l}\text { Community-level factors model } \\
\text { AOR }(95 \% \mathrm{Cl})\end{array}$ & $\begin{array}{l}\text { Individual-level factors model } \\
\text { AOR }(95 \% \mathrm{Cl})\end{array}$ & $\begin{array}{l}\text { Combined model } \\
\text { AOR }(95 \% \mathrm{Cl})\end{array}$ \\
\hline 1 & & & 1 & 1 \\
\hline $2+4$ & & & $0.93(0.90,0.96)$ & $0.96(0.93,1.02)$ \\
\hline $5+$ & & & $0.78(0.75,0.81)$ & $0.97(0.95,1.03)$ \\
\hline \multicolumn{5}{|l|}{ Birth size } \\
\hline Low birth weight & & & 1 & 1 \\
\hline Normal & & & $1.08(1.05,1.11)$ & $0.99(0.98,1.02)$ \\
\hline \multicolumn{5}{|c|}{ Random Effects results } \\
\hline Variance & $0.31(0.27,0.35)$ & $0.26(0.22,0.29)$ & $0.24(0.21,0.27)$ & $0.25(0.22,0.29)$ \\
\hline ICC & 8.66(7.76,9.66) & $7.32(6.50,8.25)$ & $6.83(6.03,7.73)$ & $7.28(6.44,8.23)$ \\
\hline PCV & 1 & 16.67 & 22.75 & 17.30 \\
\hline MOR & $1.70(1.60,1.75)$ & $1.62(1.57,1.67)$ & $1.59(1.54,1.64)$ & $1.62(1.57,1.67)$ \\
\hline \multicolumn{5}{|l|}{ Model Comparison } \\
\hline LL & ا́ 195,756 & ا́ 191,618 & أ 138,007 & ا́ 136,767 \\
\hline Deviance & 391,512 & 383,236 & $2,760,014$ & 273,534 \\
\hline AIC & 391,517 & 383,248 & 276,052 & 273,581 \\
\hline $\mathrm{BIC}$ & 391,538 & 383,311 & 276,247 & 273,817 \\
\hline
\end{tabular}

*=significant at alpha $5 \%$

who had occupations were increased by $4 \%$ as compared to women who had no occupation $(\mathrm{AOR}=1.04,95 \% \mathrm{CI}$ : $1.02,1.06)$. The odds of postnatal care service utilization was $1.70(\mathrm{AOR}=1.70,95 \% \mathrm{CI}: 1.67,1.74)$ times higher among women who exposed to media as compared to its counterpart. The odds of postnatal care service utilization among women who had antenatal care service visit during their pregnancy was 2.93 times higher as compared to women who had no ANC visit (AOR = 2.93, 95\% CI: 2.84, 3.03). The odds of postnatal care service utilization among women who deliver their newborn from the health institution were 1.45 times higher as compared to women who deliver their baby at home ( $\mathrm{AOR}=1.45,95 \% \mathrm{CI}: 1.45,1.48)$. The odds of postnatal care utilization were increased by $4 \%$ among women who reported accessing health care not a big problem as compared to its counterpart (AOR $=1.04,95 \% \mathrm{CI}$ : 1.02 , 1.06) (Table 3).

\section{Discussion}

This analysis was aimed at quantifying postnatal care service utilization and associated factors among sab Saharan countries women using the 2016 DHS data sets. Postnatal care has been approved to be an important maternal health service to keep and improve the health and survival of a mother and her newborn. Therefore, identifying the magnitude and factors of postnatal care may offer evidence for countries to reshape their policy directions.
This analysis discovered that $52.48 \%$ of women had utilized post-natal care service with a 95\% confidence interval of 52.23 to $52.63 \%$. This finding was lower than the 2013/14 DHS analysis report in Zambia (63\%) [2]. (63\%) (25). Though, this finding was higher than the 2016 DHS report 6.9\% in Ethiopia [16], 2013 DHS 29\% in Nigeria [18], 2015/2016 DHS 48.4\% in Malawi [17], and a systematic review conducted in developing countries (36\%) [12]. The possible reason for the observed difference might be occurred due to the existence of health system infrastructure and socio-cultural variations across countries. The possible reason for these differences might be due to several and complex factors, for instance, variations of policies against maternal health services, variability of quality of care and other factors like circumstances, value, understandings of postnatal care service [19].

Variables like residence, age group, maternal education, maternal occupation, media exposure, ANC visit, place of delivery, and accessing health care were statistically associated with postnatal care utilization in SubSaharan Africa.

Women who reside in an urban area had 1.14 times more likely to postnatal care utilization than women living in rural areas. This finding is supported by many other studies that showed a positive relationship between urban residency and postnatal care service utilization $[2,5,9]$. The discrepancy may be explained by physical proximity of health facilities, availability of better roads and transportation in urban than rural areas 
[20], and other possible causes of the discrepancy, maternal health services might be concentrated in urban areas than rural areas. Moreover, consciousness of maternal health services could be higher in urban areas than in rural areas.

The likelihood of postnatal care utilization among women of age group 25-34 and 35-49 were 1.07 and 1.15 time higher 1.07 and 1.15 as compared to women age group 15-24 respectively. These findings are supported a study conducted somewhere else $[12,17]$. The possible explanation for this positive relationship might be because as women's age increase the probability of health service experience on postnatal care will be better. Women who had primary and secondary and above educational levels had 1.15 and 1.11 times more likely to utilize postnatal care than women who had no formal education This finding agrees with other studies $[5,18,21]$. This can be due to as women become empowered, they could have information on advantages of postnatal care service utilization and they would be encouraged to have that service.

The odds of postnatal care utilization among women who had occupations were increased by $4 \%$ as compared to women who had no occupation This finding agrees with other reports elsewhere [17]. This can be explained as women have occupation the likely hood of being economic dependent decreases, as a result, they would have the chance to get the postnatal care service. The likelihood of postnatal care utilization was 1.70 times higher among women who exposed to media as compared to its counterpart. This finding is supported by other studies report somewhere else $[4,9]$. This finding might be attributed to the fact that women who have access to media may tend to be aware of what complications they may confront when they fail to have postnatal visits. and use maternal health services to protect their health. The likelihood of postnatal care utilization among women who had antenatal care visit during their pregnancy was 2.93 times higher as compared to women who had no ANC visit. This finding is consistent with other findings reported somewhere else $[6,21]$. This can be explained by the fact that during antenatal care service counseling, mothers could also be counseled on postnatal care services.

The odds of postnatal care utilization among women who deliver their newborn from the health institution were 1.45 times higher as compared to women who deliver their babies at home. This finding is in line with other reports elsewhere [2, 17, 22]. As mothers get deliver at health facilities, they are more likely to have counseling on postnatal care services and danger signs as well as exposed to health education. The odds of postnatal care utilization were increased by $4 \%$ among women who reported accessing health care not a big problem as compared to its counterpart This finding is consistent with another study in Nigeria [9]. This can be explained by the fact that women perceived that access to a health facility is not a big problem might be encouraged to have postnatal care services.

\section{Strength and limitation of the study}

About the strengths, the dataset used in this study was obtained from nationally representative and the variables in the 36 Africa country DHS dataset were the same hence comparable across all countries. The study was population-based with a response rate of $>90 \%$. The data were pooled together to create a large sample size of postnatal care service utilization reported within 5 years preceding each country survey which ranges from 2006 to 2018. It was able to identify the significant determinants of postnatal care service utilization across the 36 African Countries to inform policymakers and planners for their intervention to prioritize.

Regarding the limitations, the finding from this study may not establish a true causal relationship between the outcome variable and independent variables due to the cross-sectional nature of the study design. The data was collected based on self-report from mothers within 5 years preceding the survey and this could be a potential source of recall and misclassification bias.

\section{Conclusion}

The coverage of postnatal care service utilization was low with high disparities among the region. Being a rural residence, young age group, low education level, had no occupation, not exposed to media, a big problem to access health care, not had ANC visit, and home delivery was associated with low postnatal care service utilization. This study evidenced that there is a wide gap in postnatal care utilization between SSA countries. Special attention is required to improve health accessibility, utilization, and quality of maternal health services to increase postnatal care service utilization in the region.

\section{Abbreviations \\ ANC: Antenatal Care; AOR: Adjusted Odds Ratio; Cl: Confidence Interval; DHS: Demographic Health Survey; ICC: Intra-class Correlation Coefficient; LLR: Log-likelihood Ratio; LR: Likelihood Ratio; MOR: Median Odds Ratio; SSA: Sub-Saharan Africa; WHO: World Health Organization}

\section{Acknowledgements}

We greatly acknowledge the measure DHS program for granting access to the sub-Saharan African DHS data sets.

\section{Authors' contributions}

$Z T T$, LY, ABT, and GAT conceived the study. ZTT, LY, ABT, and GAT analyzed the data, drafted the manuscript, and reviewed the article. ZIT, LY, ABT, and GAT extensively reviewed the article. All authors read and approved the final manuscript.

Funding

No funding was obtained for this study. 


\section{Availability of data and materials}

Data is available online and you can access it from www.measuredhs.com

\section{Ethics approval and consent to participate}

The study was based on secondary analysis of existing survey data with all identifying information removed. Permission for data access was obtained from measure demographic and health survey through an online request from http://www.measuredhsprogram.com.

\section{Consent for publication}

Not applicable since the study was a secondary data analysis.

\section{Competing interests}

Authors declare that they have no conflict of interest.

\section{Author details}

'Department of Epidemiology and Biostatistics, Institute of Public Health, College of Medicine and Health Sciences, University of Gondar, Gondar, Ethiopia. ${ }^{2}$ Department of Health Systems and Policy, Institute of Public Health, College of Medicine and Health Sciences, University of Gondar, Gondar, Ethiopia.

Received: 17 August 2020 Accepted: 23 November 2020

Published online: 27 November 2020

\section{References}

1. Abota TL, TadeleAtenafu N. Postnatal care utilization and associated factors among married women in Benchi-Maji zone, Southwest Ethiopia: a community based cross-sectional study. Ethiop J Health Sci. 2018;28(3):267†76.

2. Chungu C, Makasa M, Chola M, Jacobs CN. Place of delivery associated with postnatal care utilization among childbearing women in Zambia. Front Public Health. 2018;6:94.

3. Chhetri S, Shah R, Rajbanshi L. Factors Associated with Utilization of Complete Postnatal Care Service in Baglung Municipality, Nepal. Int J Repro Med. 2020. p. 2020.

4. Bwalya BB, Mulenga MC, Mulenga JN. Factors associated with postnatal care for newborns in Zambia: analysis of the 2013-14 Zambia demographic and health survey. BMC Pregnancy Childbirth. 2017;17(1):418.

5. Berhe A, Bayray A, Berhe Y, Teklu A, Desta A, Araya T, et al. Determinants of postnatal care utilization in Tigray, northern Ethiopia: a community based cross-sectional study. PLoS One. 2019;14(8):e0221161.

6. Tumbure A, Argaw D, Fantahun E, Negusu M, Yitbarek T, Tadesse L, Desalegn T. Assessment of Postnatal Care Service Utilization and Associated Factors in Asella Town, Arsi Zone, Oromiya Regional State, Ethiopia.

7. Adhikari C, Yadav RK, Timilshina P, Ojha R, Gaire D, Ghimire A. Proportion and factors affecting for post-natal care utilization in developing countries: a systematic review. J Manmohan Meml Inst Heal Sci. 2016;2:14†9.

8. Akunga D, Menya D, Kabue M. Determinants of postnatal care use in Kenya. Afr Popul Stud. 2014;28(3):1447+59.

9. Agho KE, Ezeh OK, Issaka Al, Enoma Al, Baines S, Renzaho AM. Population attributable risk estimates for factors associated with non-use of postnatal care services among women in Nigeria. BMJ open. 2016;6(7).

10. Wudineh KG, Nigusie AA, Gesese SS, Tesu AA, Beyene FY. Postnatal care service utilization and associated factors among women who gave birth in Debretabour town, North West Ethiopia: a community- based crosssectional study. BMC Pregnancy Childbirth. 2018/12/29. 2018;18(1):508,

11. 2019; UN care. O. No Title. 2019.

12. Adhikari R. Effect of Women's autonomy on maternal health service utilization in Nepal: a cross sectional study. BMC Womens Health. 2016; 16(1):26.

13. Yunus A, labal S, Munawar R, Zakar R, Mushtaq SK, Sadaf F, et al. Determinants of postnatal care services utilization in Pakistan-insights from Pakistan demographic and health survey (PDHS) 2006-07. Middle-East J Sci Res. 2013;18(10):1440+7.

14. Abebo TA, Tesfaye DJ. Postnatal care utilization and associated factors among women of reproductive age Group in Halaba Kulito Town, Southern Ethiopia. Arch Public Health. 2018;76(1):1+10.

15. Kassie B, Desta M, Chanie H, Tesfaye B, Wubetu M, Alene M, et al. Postnatal care service utilization and associated factors in Ethiopia: a systematic review and Meta-analysis. 2019;.
16. Sisay MM, Geremew TT, Demlie YW, Alem AT, Beyene DK, Melak MF, et al. Spatial patterns and determinants of postnatal care use in Ethiopia: findings from the 2016 demographic and health survey. BMJ Open. 2019;9(6):1+9.

17. Khaki J. Factors associated with the utilization of postnatal care services among Malawian women. Malawi Med J. 2019;31(1):2+11.

18. Dahiru T, Oche OM. Determinants of antenatal care, institutional delivery and postnatal care services utilization in Nigeria. Pan African Med J. 2015; 22(1).

19. Benova L, Owolabi O, Radovich E, Wong KLM, Macleod D, Langlois EV, et al. Provision of postpartum care to women giving birth in health facilities in sub-Saharan Africa: a cross-sectional study using demographic and health survey data from 33 countries. PLoS Med. 2019;16(10):e1002943.

20. Tarekegn SM, Lieberman LS, Giedraitis V. Determinants of maternal health service utilization in Ethiopia: analysis of the 2011 Ethiopian demographic and health survey. BMC Pregnancy Childbirth. 2014;14(1):161.

21. Hordofa MA, Almaw SS, Berhanu MG, Lemiso HB. Postnatal care service utilization and associated factors among women in Dembecha District, Northwest Ethiopia. Sci J Public Health. 2015;3(5):686†92.

22. Rwabufigiri BN, Mukamurigo J, Thomson DR, Hedt-Gautier BL, Semasaka JPS Factors associated with postnatal care utilisation in Rwanda: a secondary analysis of 2010 demographic and health survey data. BMC Pregnancy Childbirth. 2016:16(1):122.

\section{Publisher $\div$ s Note}

Springer Nature remains neutral with regard to jurisdictional claims in published maps and institutional affiliations.
Ready to submit your research? Choose BMC and benefit from:

- fast, convenient online submission

- thorough peer review by experienced researchers in your field

- rapid publication on acceptance

- support for research data, including large and complex data types

- gold Open Access which fosters wider collaboration and increased citations

- maximum visibility for your research: over $100 \mathrm{M}$ website views per year

At BMC, research is always in progress.

Learn more biomedcentral.com/submissions 